\title{
Sea-ice thickness and roughness in the Ross Sea, Antarctica
}

\author{
Tina Tin, Martin O. JefFries \\ Geophysical Institute, University of Alaska Fairbanks, Fairbanks, AK 99775-7320, U.S.A.
}

\begin{abstract}
Sea-ice thickness and roughness data collected on three cruises in the Ross Sea, Antarctica, showed interseasonal, regional and interannual variability. Variability was reduced to season, or age of ice floe, when sea-ice roughness values from around Antarctica were compared. There were statistically significant correlations between mean snow elevation and mean ice thickness; snow surface roughness and mean ice thickness; and snow surface roughness and ice bottom roughness, which appeared to be independent of season, geographical location and deformation history of ice floes. Our field data indicate that ice thickness can be predicted from snow elevation measurements with higher accuracy in summer. The feasibility of using snow surface roughness to infer ice thickness and ice bottom roughness is promising, and can provide us with a means to study the thickness and underside of Antarctic sea ice at good spatial and temporal resolution.
\end{abstract}

\section{INTRODUCTION}

Sea-ice thickness and roughness are important variables in the air-ice-ocean system. Changes in ice thickness affect energy exchange between ocean and atmosphere, and salt balance and light penetration of the upper ocean. Ice roughness modifies the air/ice and ice/ocean interfaces and affects ice drift and turbulent transfers of heat and momentum. Changes in thickness and ice mass can be used as signals for climate change.

Drilling holes is a reliable way to measure Antarctic seaice thickness and derive its roughness (e.g. Andreas and others, 1993; Adolphs, 1999), but it is laborious and limited to a small number of samples. Electromagnetic induction (EM) sounding, which makes use of the large difference in electrical conductivity between sea ice and sea water to detect the ice/water interface, provides a more efficient method to measure Antarctic sea-ice thickness (Haas, 1998; Worby and others, 1999). EM sounding can be used on the ice surface, or its coverage can be improved by suspending the instrument from an aircraft or ice-breaker. The laser altimeter, which can also be operated from an airborne platform, has been used to describe the frequency and height distributions of Antarctic pressure ridge sails (Granberg and Leppäranta, 1999; Haas and others, 1999). However, it is not possible to derive ice thickness directly from altimetry measurements. With the projected launches of NASA's Ice, Cloud, and land Elevation Satellite (ICESat) and the European Space Agency's Cryosat, it will be possible to derive sea-ice elevation and roughness data of high resolution, and wide spatial and temporal coverages will be available. However, the ability to derive ice thickness from these and other airborne altimetry measurements depends on our knowledge of the relations between surface elevation, roughness and ice thickness.

Since ice thickness cannot be measured directly by laser altimeters, a number of studies have been conducted to infer ice thickness from quantities measured from the surface, primarily over Arctic sea ice. Using data obtained by drilling in multi-year ice, Ackley and others (1976) compared the ability of three isostatic models to predict ice thickness from surface elevations and reported that the error in the estimated thickness was only $10 \%$ greater than drilling-based operations. Wadhams and others (1992) studied concurrent laser profiling and submarine sonar records, and found that the probability density functions of snow elevation and ice draft could be related by a ratio of the density of ice plus snow and the density of water.

In the Antarctic, there have been recent studies of the ratio between snow and ice thickness (Worby and others, 1996), and between snow elevation and ice draft (Adolphs, 1998). The present study augments those studies based on data obtained from drilling profiles with new drilling data obtained in autumn 1998 and summer 1999 in the Ross Sea, Antarctica. The focus of this paper is the operational feasibility of estimating ice thickness and ice bottom surface roughness from snow surface measurements. Snow surface elevation is an obvious parameter, but its measurement by laser altimeters generally contains errors arising from uncertainty of flight altitude and estimation of sea levels (Ishizu and others, 1999). Hence we also examine snow surface roughness as a parameter for predicting ice thickness and ice bottom surface roughness, as roughness measures fluctuations about a mean value and is not affected by the accuracy of absolute snow elevation. With the new data, we are able to examine interannual (autumn 1995 and autumn 1998) and interseasonal (autumn 1995, 1998 and summer 1999) variations in sea-ice roughness, and variations in the relationships between the snow surface and ice thickness and ice bottom surface roughness.

\section{STUDY AREA AND FIELD METHODS}

The data used in this study were obtained during three cruises on the R.V. Nathaniel B. Palmer (Fig. 1). Cruises NBP 95-3 and NBP 98-3 were in the western Ross Sea during austral autumn 1995 and 1998, respectively, and parts of their cruise tracks overlapped. NBP 99-1 was in the eastern Ross Sea 


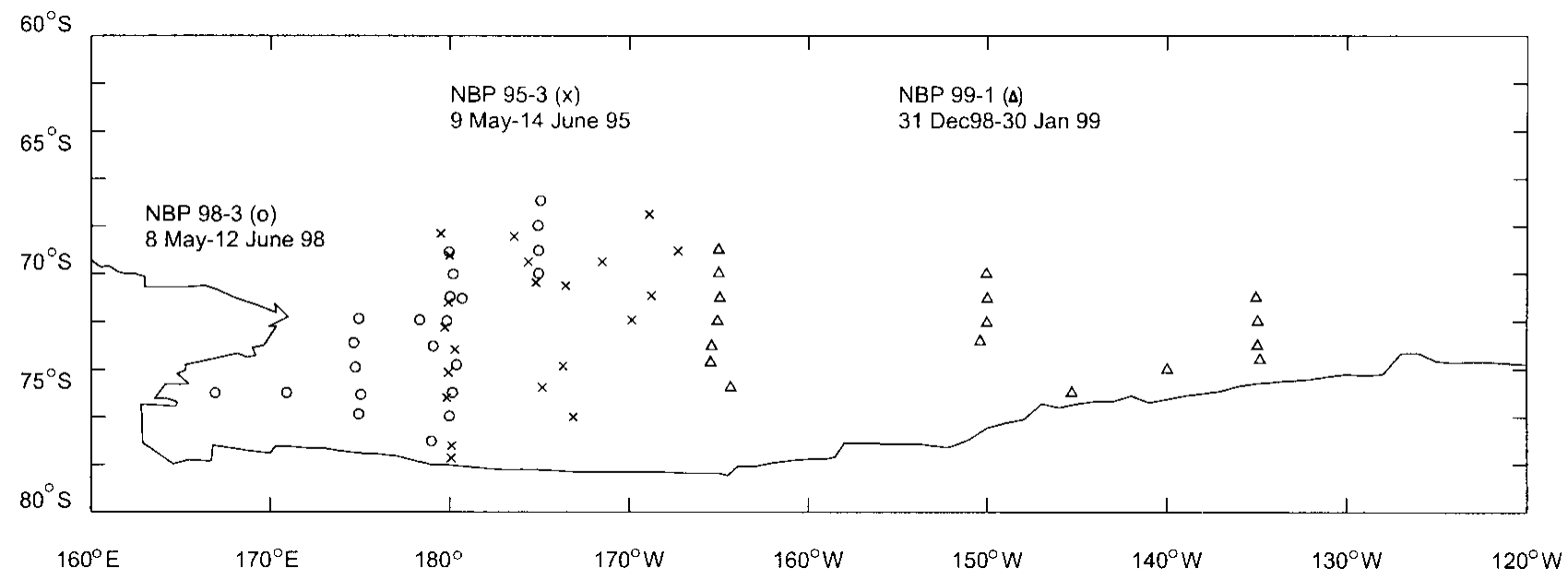

Fig. 1. Cruise tracks of NBP 95-3(×), NBP 98-3(o) and NBP 99-1 ( $\triangle)$ in the Ross Sea.



Fig. 2. A typical snow-depth and ice-thickness profile obtained during NBP 98-3, annotated to show quantities and features described in the text.

during austral summer 1999. In all three studies, data were collected by drilling at $1 \mathrm{~m}$ intervals along 50-150 $\mathrm{m}$ long transects. Only transects $\geq 100 \mathrm{~m}$ in length were analyzed. The number of transects and the total number of drillholes on each cruise are summarized in Table 1 . At each drillhole, snow thickness $\left(z_{\mathrm{s}}\right)$, ice thickness $\left(z_{\mathrm{i}}\right)$ and freeboard $\left(z_{\mathrm{f}}\right)$ were measured (Fig. 2). From these data, snow elevation $\left(h_{\mathrm{s}}=z_{\mathrm{s}}+z_{\mathrm{f}}\right)$ and draft $\left(z_{\mathrm{d}}=z_{\mathrm{i}}-z_{\mathrm{f}}\right)$ were calculated.

\section{DATA AND ANALYSIS}

\section{Roughness variance}

Roughness of the ice surface can be quantified by the roughness variance, $\sigma_{x}^{2}$ (Andreas and others, 1993). The

\section{Table 1. Summary of drilling operations}

\begin{tabular}{lcc} 
Cruise & Number of transects & Number of drillholes \\
\hline NBP 95-3 & 22 & 2221 \\
NBP 98-3 & 22 & 3131 \\
NBP 99-1 & 17 & 2517 \\
\hline
\end{tabular}

roughness variance defined for an elevation variable, $h_{x n}$ (where " $x$ " can be replaced by "s" to denote snow surface, "t" for ice top surface or " $b$ " for ice bottom surface) is defined as

$$
\sigma_{x}^{2}=\frac{1}{N} \sum_{n=1}^{N}\left(h_{x n}-\bar{h}_{x}\right)^{2},
$$

where $\bar{h}_{x}$ is the mean elevation (distance from sea level) of surface $x, N$ is the number of points on the transect and $\sigma_{x}$ is the root-mean-square ( $\mathrm{rms}$ ) elevation roughness.

\section{Data reduction}

Ridges on each floe were distinguished from unridged ice (Fig. 2) using methods similar to those applied to submarine sonar profiles under Arctic ice (Wadhams and Horne, 1980). Modifications were made for the NBP Ross Sea datasets as they were shorter in length, contained thinner ice and contained more high-frequency fluctuations. A ridge was defined by the presence of a ridge keel underwater (Fig. 2). The Rayleigh criterion defines a pressure ridge keel as one where the draft minima (troughs) on either side of the local maximum (crest) descend at least halfway toward the local level ice. In the present analysis, overlapping keels were considered as part of the same ridge. Local level horizon 
Table 2. Mean values of snow and ice thickness and roughness of ice floes for each Ross Sea dataset

\begin{tabular}{|c|c|c|c|c|c|}
\hline & $\begin{array}{c}\text { NBP 95-3 } \\
\text { (autumn } \\
1995)\end{array}$ & $\begin{array}{c}\text { NBP 98-3 } \\
\text { (autumn } \\
1998)\end{array}$ & $\begin{array}{c}\text { NBP 99-1 } \\
\text { (summer } \\
\text { 1999) }\end{array}$ & $\begin{array}{c}\text { All } \\
\text { unridged } \\
\text { regions }\end{array}$ & $\begin{array}{l}\text { All } \\
\text { ridges }\end{array}$ \\
\hline Snow thickness, $z_{\mathrm{s}}(\mathrm{m})$ & 0.14 & 0.12 & 0.32 & 0.17 & 0.22 \\
\hline Snow elevation, $h_{\mathrm{s}}(\mathrm{m})$ & 0.16 & 0.16 & 0.28 & 0.17 & 0.23 \\
\hline Freeboard, $z_{\mathrm{f}}(\mathrm{m})$ & 0.02 & 0.04 & -0.04 & 0.00 & 0.01 \\
\hline Ice thickness, $z_{\mathrm{i}}(\mathrm{m})$ & 0.63 & 0.74 & 1.08 & 0.65 & 0.92 \\
\hline $\begin{array}{l}\text { Snow surface roughness, } \\
\qquad \sigma_{\mathrm{s}}(\mathrm{m})\end{array}$ & 0.06 & 0.08 & 0.12 & 0.04 & 0.07 \\
\hline $\begin{array}{l}\text { Ice bottom surface } \\
\text { roughness, } \sigma_{\mathrm{b}}(\mathrm{m})\end{array}$ & 0.19 & 0.27 & 0.42 & 0.07 & 0.23 \\
\hline $\begin{array}{l}\text { Ice top surface roughness, } \\
\sigma_{\mathrm{t}}(\mathrm{m})\end{array}$ & 0.04 & 0.05 & 0.12 & 0.03 & 0.06 \\
\hline
\end{tabular}

was defined using the D2 definition (Wadhams and Horne, 1980). A level ice point is one whose draft differs by $<0.25 \mathrm{~m}$ from every point within $10 \mathrm{~m}$ on either side. A ridge keel must also be deeper than a minimum draft, called the cutoff value; 5 and $9 \mathrm{~m}$ cut-offs were frequently used for the Arctic sonar profiles. These values were inappropriate for the NBP Ross Sea dataset, since the maximum draft measured was only $2.5 \mathrm{~m}$ and the mean draft was $0.80 \mathrm{~m}$. The size difference between Arctic and Antarctic ridges was also noted by Worby and others (1996), who reduced the cut-off heights for ridge sails to $0.5 \mathrm{~m}$ from the usual values of $0.75^{-1} \mathrm{~m}$ to allow for the smaller ridges in the Amundsen and Bellingshausen Seas. We tested the NBP Ross Sea dataset with cut-off values of $1,0.75$ and $0.5 \mathrm{~m}$ for ridge keels. We found that cut-off values of 0.75 and $1 \mathrm{~m}$ missed a significant portion of ridges $(72 \%$ and $55 \%$, respectively), while a cut-off value of $0.5 \mathrm{~m}$ captured $80 \%$ of the ridges. Hence, we adopted the definition that a ridge keel is an underwater feature which satisfies the Rayleigh criterion and is at least $0.5 \mathrm{~m}$ deep.
Each identified ridge is represented as an individual data point in the following analysis. Once the ridges were removed, each one of the remaining regions is classified as unridged ice (Fig. 2) and is represented as an individual data point.

\section{RESULTS}

\section{Mean thickness and roughness}

The mean thickness and roughness values were reasonably similar for the two autumn cruises (NBP 95-3 and NBP 98-3), and these cruises were dissimilar to the summer cruise (NBP 99-1) (Table 2). Summer ice was thicker and had a deeper snow cover. As a result of the heavy snow load, the summer snow/ice interface was often submerged below sea level, and mean summer freeboard was $-0.04 \mathrm{~m}$. The roughness of the summer ice and snow surfaces was around twice as great as that of autumn ice. For the autumn cruises, there was slightly thicker ice, thinner snow and rougher surfaces in 1998 than in 1995.

Ridges contained thicker ice, deeper snow and rougher ice bottom surfaces than unridged regions (Table 2). At the ice bottom surface, ridges were nearly four times as rough as unridged regions, but ice top surface and snow surface were similar in roughness. Mean freeboards of both ridges and unridged regions were at or close to zero.

\section{Linear regressions}

Linear regressions were performed between mean snow elevation, $h_{\mathrm{s}}$, and mean ice thickness, $z_{\mathrm{i}}$ (Fig. 3a-f); snow surface roughness, $\sigma_{\mathrm{s}}$, and mean ice thickness, $z_{\mathrm{i}}$ (Fig. $4 \mathrm{a}-\mathrm{f}$ ); snow surface roughness, $\sigma_{\mathrm{s}}$, and ice bottom roughness, $\sigma_{\mathrm{b}}$ (Fig. 5a-f); and snow surface roughness, $\sigma_{\mathrm{s}}$, and ice top surface roughness, $\sigma_{\mathrm{t}}($ Fig. $6 \mathrm{a}-\mathrm{c})$. The majority of correlations are significant at the $99 \%$ confidence level.

Cruises varied in the strength of correlation between each pair of variables. For example, correlation between $h_{\mathrm{s}}$

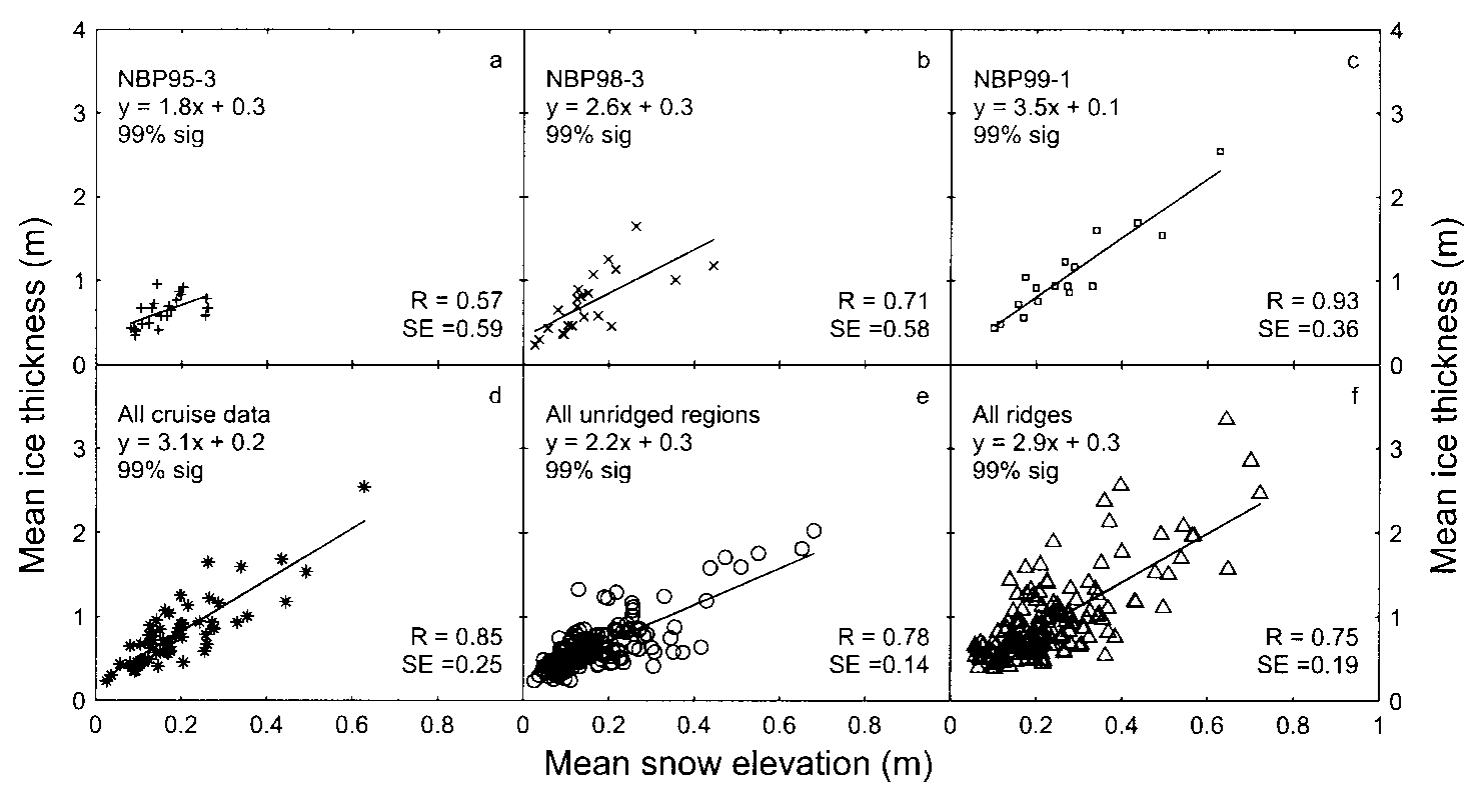

Fig. 3. Linear regression between mean snow elevation $\left(h_{\mathrm{s}}\right)$ and mean ice thickness $\left(z_{\mathrm{i}}\right) .(a-c)$ Roughnesses averaged over each entire profile for individual cruises; (d) linear regression of all cruise data combined; $(e, f)$ roughnesses over individual unridged regions and ridges, respectively. The correlation coefficient $(R)$, the significancelevel (\% sig) and the standard error (SE) of the slope of the regression are given in each graph. Plus/minus 2 SE corresponds to $95 \%$ confidence interval of the regression. 


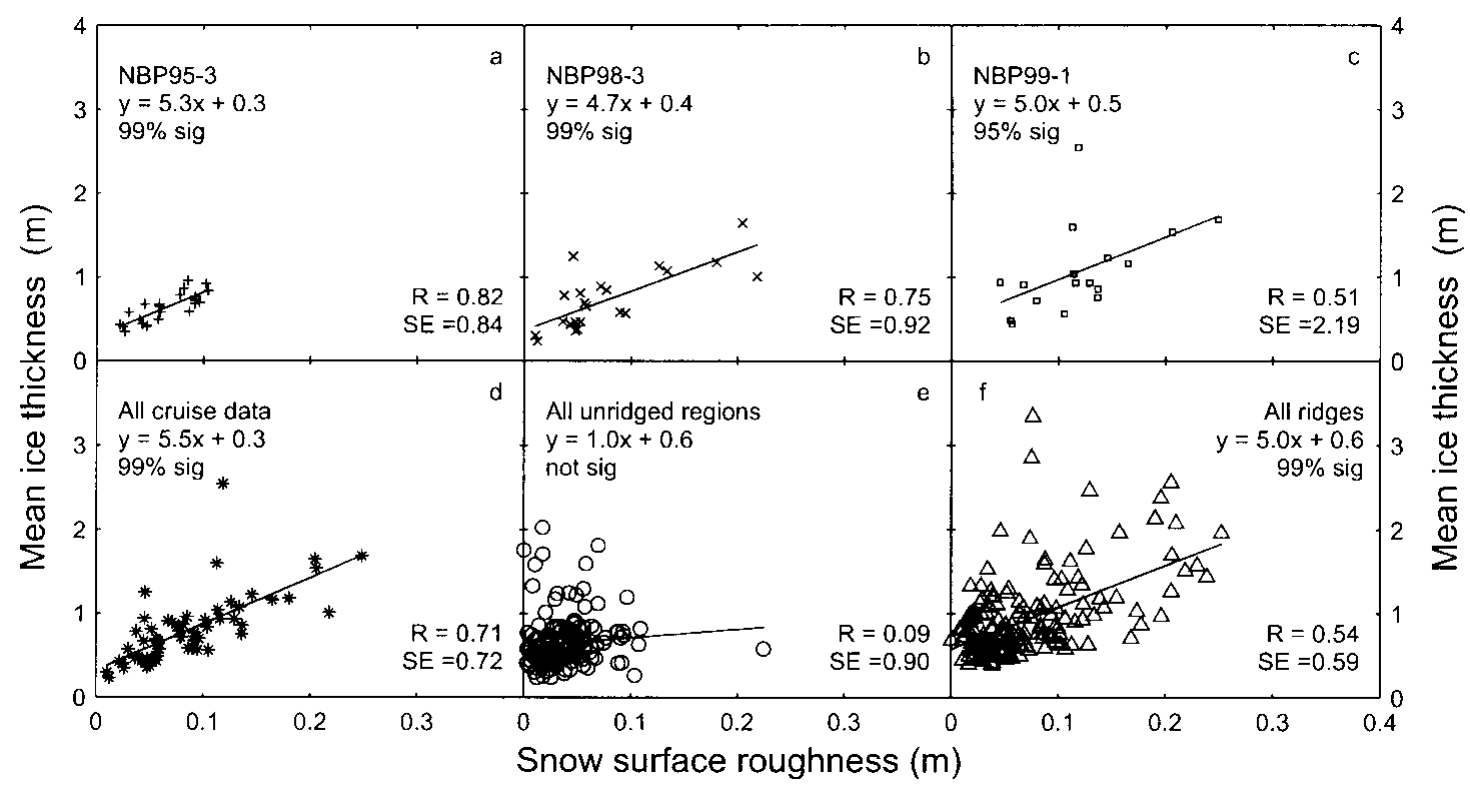

Fig. 4. Linear regression between snow surface roughness $\left(\sigma_{\mathrm{s}}\right)$ and mean ice thickness $\left(z_{\mathrm{i}}\right) .(a-c)$ Roughnesses averaged over each entire profile for individual cruises; $(d)$ linear regression of all cruise data combined; $(e, f)$ roughnesses over individual unridged regions and ridges, respectively.

and $z_{\mathrm{i}}$ was considerably stronger in NBP 99-1 than in NBP 95-3 or NBP 98-3 (Fig. 3a-c); correlation between $\sigma_{\mathrm{s}}$ and $z_{\mathrm{i}}$ was stronger in NBP 95-3 and NBP 98-3 than in NBP 99-1 (Fig. $4 \mathrm{a}-\mathrm{c}$ ); and scatter between $\sigma_{\mathrm{s}}$ and $\sigma_{\mathrm{b}}$ was considerable on all three cruises (Fig. $5 \mathrm{a}-\mathrm{c}$ ). However, for each pair of variables, the data points from all three cruises converge relatively well along a linear trend (Figs $3 \mathrm{~d}, 4 \mathrm{~d}$ and $5 \mathrm{~d}$ ). The strongest correlation was between $h_{\mathrm{s}}$ and $z_{\mathrm{i}}(R \sim 0.85$; Fig. 3d), while the correlations between $\sigma_{\mathrm{s}}$ and $z_{\mathrm{i}}$ (Fig. $4 \mathrm{~d}$ ) and between $\sigma_{\mathrm{s}}$ and $\sigma_{\mathrm{b}}$ (Fig. $5 \mathrm{~d}$ ) were slightly weaker and similar in strength $(R \sim 0.71)$. Despite the similarity in correlation coefficients, scatter between $\sigma_{\mathrm{s}}$ and $\sigma_{\mathrm{b}}$ was considerably greater than between $\sigma_{\mathrm{s}}$ and $z_{\mathrm{i}}$.

Regressions for ridges and unridged regions differed among the variable pairs. There was stronger correlation between $h_{\mathrm{s}}$ and $z_{\mathrm{i}}$ for both ridges and unridged regions
(Fig. 3e and f). Weaker correlation and large data scatter were found for both ridges and unridged regions between $\sigma_{\mathrm{s}}$ and $z_{\mathrm{i}}, \sigma_{\mathrm{s}}$ and $\sigma_{\mathrm{b}}, \sigma_{\mathrm{s}}$ and $\sigma_{\mathrm{t}}$ (Figs $4 \mathrm{e}$ and $\mathrm{f}, 5 \mathrm{e}$ and $\mathrm{f}$ and $6 \mathrm{~b}$ and $\mathrm{c}$ ), with the correlation being considerably stronger for ridges than for unridged regions.

\section{DISGUSSION}

\section{Mean thickness and roughness}

Interseasonal, regional and interannual variations were observed in the thickness and roughness of Ross Sea ice. Ice and snow were thicker and surfaces were rougher in NBP 991 than in NBP 95-3 and NBP 98-3. The autumn ice in NBP 953 and NBP 98-3 contained a higher fraction of thin, new ice than the summer ice in NBP 99-1. By the summer, the ice

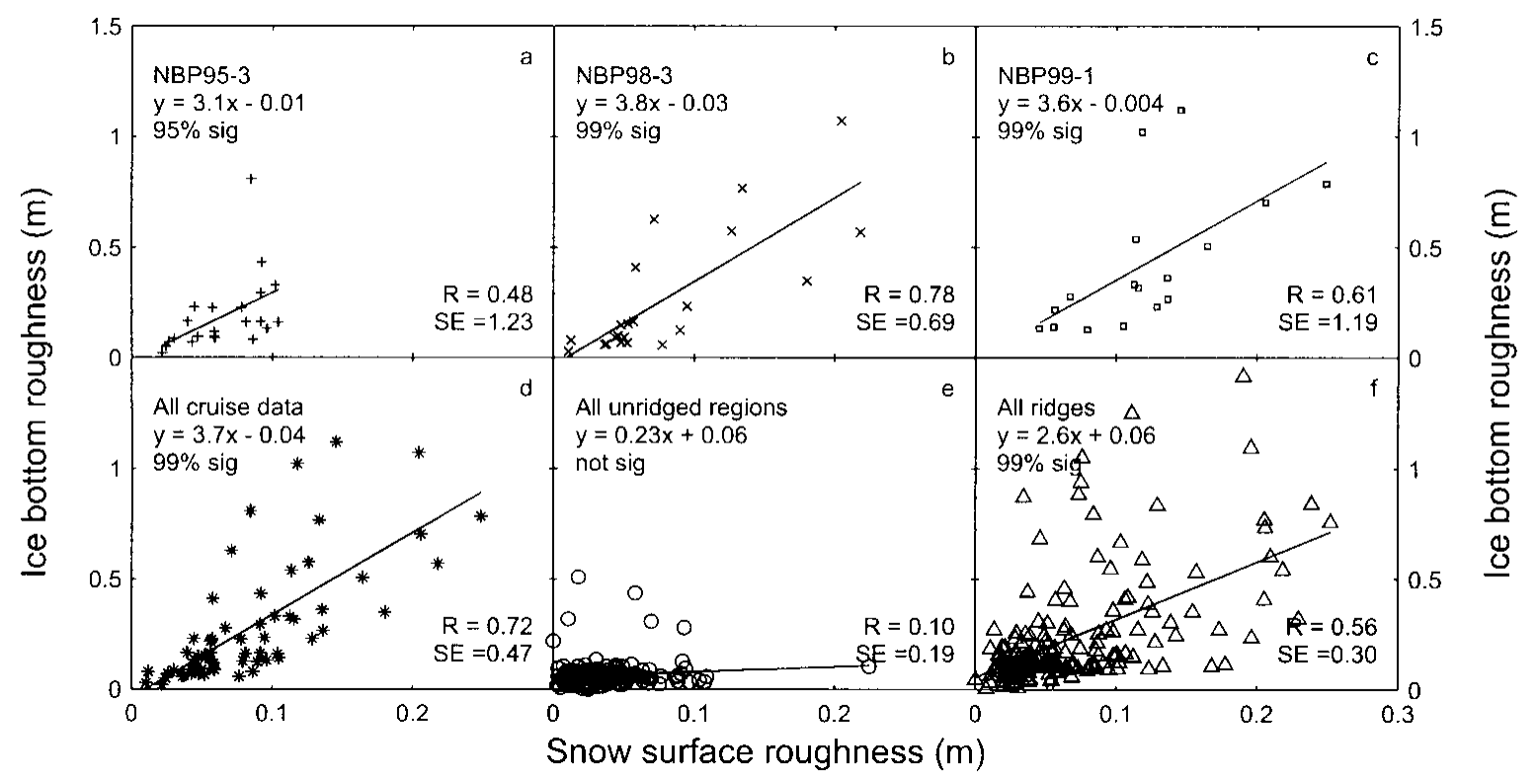

Fig. 5. Linear regression between snow surface roughness $\left(\sigma_{\mathrm{s}}\right)$ and ice bottom roughness $\left(\sigma_{\mathrm{b}}\right) .(a-c)$ Roughnesses averaged over each entire profile for individual cruises; (d) linear regression of all cruise data combined; $(e, f)$ roughnesses over individual unridged regions and ridges, respectively. 


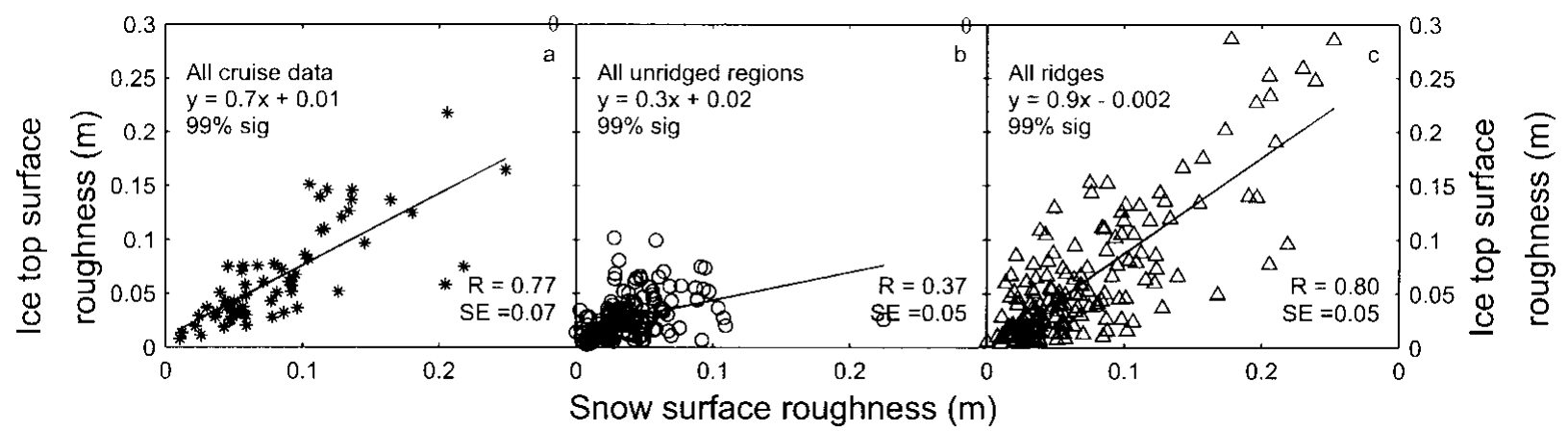

Fig. 6. Linear regression between snow surface roughness $\left(\sigma_{\mathrm{s}}\right)$ and ice top surface roughness $\left(\sigma_{\mathrm{t}}\right)$. (a) Linear regression of all cruise data combined; $(b, c)$ roughnesses over individual unridged regions and ridges, respectively.

cover had had time to thicken both dynamically and thermodynamically, and to accumulate snow. NBP 99-1 took place in the eastern Ross Sea where winds are more variable and ice export is less effective than in the western Ross Sea (Marshall and Turner, 1997), where katabatic winds of high directional constancy and the cyclonic circulation of the Ross Sea maintain efficient ice export (Jacobs and Comiso, 1989). Consistently high concentrations of sea ice (Sturman and Anderson, 1986) and variable winds (Marshall and Turner, 1997) in the eastern Ross Sea promote dynamic thickening and roughening of ice surfaces. The snow surface in this region could also roughen as a result of variable winds, floe rotation (Massom and others, 1997) and increased ice deformation. Interannual variability was observed between NBP 95-3 and NBP 98-3, which took place in the same season and similar geographical locations, with 1998 being a year of less snow accumulation and greater ice thickness and roughness.

Ridges and unridged regions exhibited different characteristics, with ridges having a rougher ice bottom, greater ice thickness and accumulating more snow. Despite the differences in snow loading and ice stresses, isostatic balance was maintained across both ridges and unridged regions, as reflected by their mean freeboards of zero.

\section{Comparison of surface roughness with other Antarctic regions}

Sea-ice roughness values from various studies were compared according to geographical location, season and ice type (Table 3). Roughness values fell into two categories according to the age of ice floes. Early season (autumn to spring) firstyear ice was low in roughness (Table 3). Late season (summer) first-year ice was similar to multi-year ice (Table 3) where roughness was up to three times that of early season first-year ice. From NBP 95-3, NBP 98-3 and NBP 99-1, we observed interannual, regional and interseasonal variability in sea-ice roughness (Table 2). When the comparison was expanded to include eight other cruises from previous studies in other parts of Antarctica, we found that interseasonal variations stood out over interannual and regional variability for first-year ice (Table 3). For the multi-year ice in the western Weddell Sea, roughness values were consistent among measurements made in different years and seasons (Table 3). This suggests that processes which create sea-ice roughness are independent of year and location, and that ice-floe age and deformation history are the most important factors in determining roughness.

Table 3. Comparison of rms snow and sea-ice roughness values $(m)$ in Antarctica

\begin{tabular}{|c|c|c|c|c|c|c|}
\hline Source & Location & Season & Ice type & $\begin{array}{c}\text { Snow surface, } \\
\sigma_{\mathrm{s}}\end{array}$ & $\begin{array}{c}\text { rms roughness } \\
\text { Ice bottom surface, } \\
\sigma_{\mathrm{b}}\end{array}$ & $\begin{array}{c}\text { Ice top surface, } \\
\sigma_{\mathrm{t}}\end{array}$ \\
\hline \multicolumn{7}{|l|}{ Dataset of present study } \\
\hline NBP 95-3 & Ross Sea (west) & Autumn & Firstyear & 0.06 & 0.19 & 0.04 \\
\hline NBP 98-3 & Ross Sea (west) & Autumn & First year & 0.08 & 0.27 & 0.05 \\
\hline NBP 99-1 & Ross Sea (east) & Summer & First year & 0.12 & 0.42 & 0.12 \\
\hline \multicolumn{7}{|l|}{ Previous studies } \\
\hline Fisher and Lytle (1998) ${ }^{\mathbf{1}}$ & Weddell Sea (east) & Winter & First year & 0.07 & - & 0.04 \\
\hline Adolphs (1999) ${ }^{\mathbf{a}}$ & Ross, Amundsen and Bellinghausen Seas & Winter & First year & 0.08 & 0.25 & 0.04 \\
\hline Andreas and others (1993) ${ }^{\mathbf{a}}$ & Weddell Sea (east and west) & Spring & Firstyear & 0.09 & 0.27 & 0.07 \\
\hline Fisher and Lytle $(1998)^{2}$ & Weddell Sea (west) & Autumn & Multi-year & 0.13 & - & 0.09 \\
\hline Fisher and Lytle $(1998)^{3}$ & Weddell Sea (east) & Autumn & $\begin{array}{l}\text { Multi-year } \\
\text { (single-floe) }\end{array}$ & 0.12 & - & 0.12 \\
\hline Andreas and others $(1993)^{a}$ & Weddell Sea (west) & Spring & Multi-year & 0.08 & 0.38 & 0.13 \\
\hline
\end{tabular}

\footnotetext{
Note: Studies in italics contain early season first-year ice. Studies in bold contain late season first-year ice and multi-year ice.

${ }^{1}$ Referred to as NBP 94 in Fisher and Lytle (1998).

2 Referred to as NBP 92 in Fisher and Lytle (1998).

${ }^{3}$ Referred to as ISW in Fisher and Lytle (1998).

a Mean values estimated from graphs.
} 


\section{Linear regression}

In the linear regressions between $h_{\mathrm{s}}$ and $z_{\mathrm{i}} ; \sigma_{\mathrm{s}}$ and $z_{\mathrm{i}}$; and $\sigma_{\mathrm{s}}$ and $\sigma_{\mathrm{b}}$, we observed variations between cruises and over ridges and unridged regions (Figs $3 a-f, 4 a-f$ and $5 a-f$ ). Despite the differences in data scatter and linear regression, a good linear trend emerged for each pair of variables when all profiles from the cruises were combined. This suggests that processes maintaining the relationships between snow elevation and ice thickness; snow surface roughness and ice thickness; and snow surface roughness and ice bottom roughness, are independent of season, year, location and deformation history of the ice floes.

Correlation between $h_{\mathrm{s}}$ and $z_{\mathrm{i}}$ over ridges and unridged regions (Fig. $3 \mathrm{e}-\mathrm{f}$ ) was stronger than correlations between $\sigma_{\mathrm{s}}$ and $z_{\mathrm{i}}$ (Fig. 4e and f), and $\sigma_{\mathrm{s}}$ and $\sigma_{\mathrm{b}}$ (Fig. 5e and f). This difference is primarily due to the different mechanisms that determine $h_{\mathrm{s}}$ and $\sigma_{\mathrm{s}}$.

\section{Mean snow elevation, $h_{\mathrm{s}}$}

The stronger correlation between $h_{\mathrm{s}}$ and $z_{\mathrm{i}}$ in NBP 99-1 than in NBP 95-3 and NBP 98-3 can be attributed to the presence of slush. Slush is the layer of saturated snow between the snow/ice interface and the sea level on a flooded ice floe, where $z_{\mathrm{f}}<0$. As explained below, slush enhances the capability of predicting $z_{\mathrm{i}}$ from $h_{\mathrm{s}}$ by separating $h_{\mathrm{S}}$ from $z_{\mathrm{i}}$, and by making little contribution to buoyancy.

The isostatic balance of a non-flooded ice floe $\left(z_{\mathrm{f}} \geq 0\right)$ is as follows:

$$
\rho_{\mathrm{s}} z_{\mathrm{s}}+\rho_{\mathrm{i}} z_{\mathrm{f}}=z_{\mathrm{d}}\left(\rho_{\mathrm{w}}-\rho_{\mathrm{i}}\right) \quad \text { for } z_{\mathrm{f}} \geq 0,
$$

where $\rho_{\mathrm{S}}$ is the density of snow, $\rho_{\mathrm{i}}$ is the density of sea ice (assumed to be $900 \mathrm{~kg} \mathrm{~m}^{-3}$; Massom and others, 1998) and $\rho_{\mathrm{w}}$ is the density of sea water $\left(1024 \mathrm{~kg} \mathrm{~m}^{-3}\right)$. Mean $\rho_{\mathrm{s}}$ values for NBP 95-3, NBP 98-3 and NBP 99-1 were 340, 320 and $520 \mathrm{~kg} \mathrm{~m}^{-3}$, respectively (Sturm and others, 1998; Morris and Jeffries, 2001). Isostatic balance in a non-flooded ice floe is maintained between $h_{\mathrm{s}}\left(=z_{\mathrm{s}}+z_{\mathrm{f}}\right)$, which contains snow and some ice, and $z_{\mathrm{d}}$. Translation between $z_{\mathrm{d}}$ and $z_{\mathrm{i}}$ also depends on the isostatic balance, and the multiple dependencies make the relationship between $h_{\mathrm{s}}$ and $z_{\mathrm{i}}$ complex and scattered.

The isostatic balance of a flooded ice floe $\left(z_{\mathrm{f}}<0\right)$ is as follows:

$$
\rho_{\mathrm{s}}\left(z_{\mathrm{s}}+z_{\mathrm{f}}\right)=z_{\mathrm{i}}\left(\rho_{\mathrm{w}}-\rho_{\mathrm{i}}\right)+z_{\mathrm{f}}\left(\rho_{\mathrm{w}}-\rho_{\mathrm{sl}}\right) \quad \text { for } z_{\mathrm{f}}<0,
$$

where $z_{\mathrm{f}}$ indicates the thickness of the slush layer and $\rho_{\mathrm{sl}}$ is density of slush, which is estimated to be close to that of sea water $\left(0.96 \mathrm{~kg} \mathrm{~m}^{-3}\right)$ (Adolphs, 1998), although field measurements arrive at lower values $\left(0.70 \mathrm{~kg} \mathrm{~m}^{-3}\right)$ (Adolphs, 1998) as sea water is invariably lost during the measurement procedure. The small difference between $\rho_{\mathrm{sl}}$ and $\rho_{\mathrm{w}}$ means that the effect of slush on buoyancy is small. As a result, the isostatic balance is maintained between $h_{\mathrm{s}}$ and $z_{\mathrm{i}}$, allowing $z_{\mathrm{i}}$ to be predicted effectively from $h_{\mathrm{s}}$.

Variability in the ratio $z_{\mathrm{i}}: h_{\mathrm{s}}$ can be explained by the differences in the relative densities and proportions of ice and snow above sea level. We observed a higher $z_{\mathrm{i}}: h_{\mathrm{s}}$ ratio in NBP 99-1 (4:1) than in NBP 98-3 (3:1), which was, in turn, higher than in NBP 95-3 (2:1) (Fig. 3a-c). Snow density in NBP 99-1 was highest, being 1.5 times greater than in NBP 95-3 and NBP 98-3. For the same $h_{\mathrm{s}}$, the heavier load in NBP 99-1 required a greater buoyancy force created by a larger ice volume below the sea level. Hence the ratio of $z_{\mathrm{i}}: h_{\mathrm{s}}$ was greatest in NBP 99-1. Between NBP 95-3 and NBP 98-3, there was only $6 \%$ difference in $\rho_{\mathrm{s}}$, and $h_{\mathrm{S}}$ was the same for both years. However, there was $0.02 \mathrm{~m}$ more ice freeboard in NBP 98-3 than in NBP 95-3, and since the ice was three times more dense than snow, the load for the same $h_{\mathrm{s}}$ increased. An increased load required a larger ice volume to provide the buoyancy force, and hence the $z_{\mathrm{i}}: h_{\mathrm{s}}$ ratio was greater in NBP 98-3 than in NBP 95-3.

\section{Snow surface roughness, $\sigma_{\mathrm{s}}$}

Snow surface roughness is primarily determined by ice top surface topography and wind redistribution. Snow preferentially collects in depressions. Winds at speeds of $>6-8 \mathrm{~m} \mathrm{~s}^{-1}$ are able to redistribute the snow (Andreas and Claffey, 1995), building it up in the lee of sails, filling in between sails and keeping the tops of sails bare (Lange and Eicken, 1991). A snow surface with a hard crust would require higher winds to initiate redistribution (Andreas and Claffey, 1995). Snowdrifts on ice floes are often omnidirectional because of floe rotation and changes in prevailing wind direction (Massom and others, 1997). The snow surface amplifies the roughness of the ice top surface, and the amplification is stronger in unridged regions than in ridges (Fig. $6 \mathrm{a}-\mathrm{C}$ ). Analysis of the frequency of snow surface roughness reveals that, although the magnitude of ice roughness has been amplified, the frequency of roughness features has been decreased, resulting in a smoothing effect over the ice top surface (Andreas and Claffey, 1995; Massom and others, 1997).

The poor correlation between $\sigma_{\mathrm{s}}$ and $z_{\mathrm{i}}$ and $\sigma_{\mathrm{b}}$ over unridged regions (Figs $4 \mathrm{e}$ and $5 \mathrm{e}$ ) can be attributed to the large discrepancy between $\sigma_{\mathrm{s}}$ and $\sigma_{\mathrm{t}}$ decoupling the snow surface from the processes determining $z_{\mathrm{i}}$ and $\sigma_{\mathrm{b}}$. Why does a large discrepancy between $\sigma_{\mathrm{s}}$ and $\sigma_{\mathrm{t}}$ exist in the unridged regions and not in ridges (Fig. $6 \mathrm{~b}$ and c)? We suggest that the modification of ice top surface roughness, effects of nearby ridges and nucleation of roughness features on the snow surface are possible reasons. After the snow cover has been laid down, ice top surface can be smoothed by formation of snow ice. Snow ice is formed by the freezing of snow and floodwater at the interface between snow and ice, and this new ice layer smooths out small perturbations on the ice top surface, thereby reducing $\sigma_{\mathrm{t}}$. Hence, $\sigma_{\mathrm{t}}$ that is measured subsequent to snow-ice formation has a lower value than when the snow cover was first laid down (Worby and others, 1996). In ridges, $\sigma_{\mathrm{t}}$ is dominated by the crest of the keel or sail, with its large deviation from the mean surface. Flooding and subsequent smoothing of troughs by the growth of snow ice has a relatively small effect on the $\sigma_{\mathrm{t}}$ over the entire ridge.

Wind redistributes snow so that it builds up in the lee of ridge sails, and snowdrifts have been observed up to $10 \mathrm{~m}$ away from a ridge (Sturm and others, 1998). The roughness of this wind-drifted snow is independent of the ice top surface roughness. As a result, $\sigma_{\mathrm{s}}$ and $\sigma_{\mathrm{t}}$ are decoupled close to ridges, and unridged regions can have a disproportionately large $\sigma_{\mathrm{s}}$. On flat level ice surface, $\sigma_{\mathrm{s}}$ can also be decoupled from $\sigma_{\mathrm{t}}$, as small icy nodules with sub-centimeter diameters can act as the foci for the formation of extensive dune features which can be up to $1 \mathrm{~m}$ high and $35 \mathrm{~m}$ long (Massom and others, 1997; Sturm and others, 1998). 


\section{CONGLUSIONS}

Interseasonal, regional and interannual variations were observed in the thickness and roughness of Ross Sea ice. Variability was reduced to season, or age of ice floe, when sea-ice roughness values from around Antarctica were compared. This suggests that processes which create sea-ice roughness are independent of year and location, and that ice-floe age and deformation history are the most important components in determining roughness. We found statistically significant correlations between mean snow elevation and mean ice thickness; snow surface roughness and mean ice thickness; and snow surface roughness and ice bottom roughness, over profiles $\geq 100 \mathrm{~m}$ in length. The correlations appeared to be independent of season, location and deformation history of ice floes. The predictive capability of snow elevation and snow surface roughness is promising. The presence of slush improves the capability to predict ice thickness from snow surface elevation by keeping all ice below sea level and by making little contribution to buoyancy.

To improve and further understand the predictive capability of snow elevation and snow surface roughness, more data in the high thickness and roughness range (mean ice thickness $>1.5 \mathrm{~m}$, snow surface roughness $>0.15 \mathrm{~m}$ and ice bottom roughness $>0.75 \mathrm{~m}$ ) is needed. Monitoring the effects of wind on snow surface roughness and the modification of the ice top surface through the season will improve our understanding of the mechanisms which determine snow surface roughness. Finally, similar studies in other parts of the Southern Ocean can tell us whether a single relationship of snow elevation and snow surface roughness with ice thickness and ice bottom roughness can be applied for all ice-covered waters in Antarctica. The bottom surface of Antarctic sea ice has only been studied by moored upward-looking sonars (Strass and Fahrbach, 1998) or by drilling profiles (e.g. Lange and Eicken, 1991; Worby and others, 1996), and data are limited in spatial coverage. Unless autonomous underwater vehicles or civilian submersibles become available for research under the Antarctic sea-ice cover, the established methods are the only ways to directly obtain information on ice thickness, ice bottom roughness and ice bottom topography. The ability to predict subsurface quantities from airborne or even spaceborne measurements will provide us with an indirect method that has good spatial and temporal coverage to study the thickness and underside of Antarctic sea ice.

\section{ACKNOWLEDGEMENTS}

This work was supported by U.S. National Science Foundation grants OPP-9316767 and OPP-9614844. We are grateful to the many members of the science teams and Antarctic Support Associates personnel who dug snow, drilled holes and made measurements. We also thank Captain J. Borkowski and the officers and crew of R.V. Nathaniel B. Palmer for their vital contribution. Thanks also to reviewers C. Haas and S. Ackley and editor T. Tucker for providing invaluable suggestions that helped to improve the paper.

\section{REFERENGES}

Ackley, S. F., W. D. Hibler, III, F. K. Kugzruk, A. Kovacs and W. F. Weeks. 1976. Thickness and roughness variations of Arctic multi-year sea ice. CRREL Rep. 76-18.

Adolphs, U. 1998. Ice thickness variability, isostatic balance and potential for snow ice formation in ice floes in the south polar Pacific Ocean. 7. Geophys. Res., $103(\mathrm{Cl}), 24,675-24,691$.

Adolphs, U. 1999. Roughness variability of sea ice and snow cover thickness profiles in the Ross, Amundsen, and Bellingshausen Seas. 7. Geophys. Res., 104(C6), 13,577-13,591.

Andreas, E. L. and K. J. Claffey. 1995. Air-ice drag coefficients in the western Weddell Sea. 1. Values deduced from profile measurements. 7. Geophys. Res., 100 (C3), 4821-4831.

Andreas, E. L., M. A. Lange, S. F. Ackley and P. Wadhams. 1993. Roughness of Weddell Sea ice and estimates of the air-ice drag coefficient. 7. Geophys. Res., 98(C7), 12,439-12,452.

Fisher, R. and V. I. Lytle. 1998. Atmospheric drag coefficients of Weddell Sea ice computed from roughness profiles. Ann. Glaciol., 27, 455-460.

Granberg, H. B. and M. Leppäranta. 1999. Observations of sea ice ridging in the Weddell Sea. F. Geophys. Res., 104(C11), 25,735-25-745.

Haas, C. 1998. Evaluation of ship-based electromagnetic-inductive thickness measurements of summer sea-ice in the Bellinghausen and Amundsen Seas, Antarctica. Cold Reg. Sci. Technol., 27(1), 1-16.

Haas, C., Q. Liu and T. Martin. 1999. Retrieval of Antarctic sea-ice pressure ridge frequencies from ERS SAR imagery by means of in-situ laser profiling and usage of a neural network. Int. F. Remote Sensing, 20(15-16), $3111-3123$.

Ishizu, M., K. Mizutani andT. Itabe. 1999. Airborne freeboard measurements of sea ice and lake ice at the Sea of Okhotsk coast in 1993-95 by a laser altimeter. Int. F. Remote Sensing, 20(12), 2461-2476.

Jacobs, S. S. and J. C. Comiso. 1989. Sea ice and oceanic processes on the Ross Sea continental shelf. 7. Geophys. Res., 94(C12), 18,195-18,211.

Lange, M. A. and H. Eicken. 1991. The sea-ice thickness distribution in the northwestern Weddell Sea. 7. Geophys. Res., 96(C3), 4821-4837.

Marshall, G. J. and J. Turner. 1997. Katabatic wind propagation over the western Ross Sea observed using ERS-1 scatterometer data. Antarct. Sci., 9(2), 221-226.

Massom, R. A., M. R. Drinkwater and C. Haas. 1997. Winter snow cover on sea ice in the Weddell Sea. 7. Geophys. Res., 102(Cl), 1101-1117.

Morris, K. and M. O. Jeffries. 2001. Seasonal contrasts in snow-cover characteristics on Ross Sea ice floes. Ann. Glaciol., 33 (see paper in this volume).

Strass, V. H. and E. Fahrbach. 1998. Temporal and regional variation of seaice draft and coverage in the Weddell Sea obtained from upward looking sonars. In Jeffries, M. O., ed. Antarctic sea-ice: physical processes, interactions and variability. Washington, DC, American Geophysical Union, 123-139. (Antarctic Research Series 74.)

Sturm, M., K. Morris and R. Massom. 1998. The winter snow cover of the West Antarctic pack ice: its spatial and temporal variability. In Jeffries, M. O., ed. Antarctic sea-ice: physical processes, interactions and variability. Washington, DC, American Geophysical Union, 1-18. (Antarctic Research Series 74.)

Sturman, A. P. and M. R. Anderson. 1986. On the sea-ice regime of the Ross Sea, Antarctica. 7. Glaciol., 32(110), 54-59.

Wadhams, P. and R. J. Horne. 1980. An analysis of ice profiles obtained by submarine sonar in the Beaufort Sea. f. Glaciol., 25(93), 401-424; Erratum: 27 (96), 1981, p. 367.

Wadhams, P., W. B. Tucker, III, W. B. Krabill, R. N. Swift, J. C. Comiso and N. R. Davis. 1992. Relationship between sea-ice freeboard and draft in the Arctic Basin, and implications for ice thickness monitoring. 7. Geophys. Res., 97 (C12), 20,325-20,334.

Worby, A. P., M. O. Jeffries, W. F. Weeks, R. Morris and R. Jaña. 1996. The thickness distribution of sea ice and snow cover during late winter in the Bellingshausen and Amundsen Seas, Antarctica. 7. Geophys. Res., $101(\mathrm{Cl} 2), 28,441-28,455$.

Worby, A. P., P. W. Griffin, V. I. Lytle and R. A. Massom. 1999. On the use of electromagnetic induction sounding to determine winter and spring sea-ice thickness in the Antarctic. Cold Reg. Sci. Technol., 29(1), 49-58. 